\title{
BLOG VERSÃO PAULO: A PROSPECÇÃo do PASSAdo COMO MANEIRA DE PENSAR O PRESENTE E O FUTURO DA CIDADE
}

\author{
BLOG VERSÃO PAULO: \\ THE EXPLORATION OF THE PAST AS A WAY OF THINKING ABOUT THE \\ PRESENT AND FUTURE OF THE CITY
}

v.8, n.2 [13]

mai/ago (2016)

Dossiê: Cidade e Natureza
Paula Janovitch Pesquisadora USP paulajano@gmail.com

\section{Resumo}

A partir da apresentação de alguns posts do blog Versão Paulo que abordam a relação da cidade no final do século XIX com o desequilíbrio ambiental e a maneira como a sociedade passa a se relacionar com as escalas de tempo e espaço, gostaria de discutir as possibilidades da história, através de sua abordagem do passado, pensar problemas ambientais que perpassam a vida urbana até os dias de hoje.

\section{Palavras-chave}

Desequilíbrio ambiental. Problemas urbanos. Escalas de tempo e espaço.

\begin{abstract}
Based on the presentation of some posts from the blog Versão Paulo which refer to the relationship between the city in the late nineteenth century and the environmental unbalance and also the way the society start to relate with the scales of time and space, I would like to discuss the history's possibilities, think about environmental issues that permeate the urban life until these days through the approach of the past.
\end{abstract}

Keywords

Environmental unbalance. Urban problems. Scales of time and space. 


\section{Desenvolvimento do artigo}

Aceitei participar deste I Seminário de Pesquisa Cidade e Natureza, porque de fato nos últimos anos venho escolhendo temas e produzindo pequenos ensaios em formato de posts que se concentram na cidade e, nada por acaso, muitas vezes, o assunto que escolho são temas relativos a sua relação com a natureza e as transformações que a presença de novas tecnologias produziu no meio urbano.

A partir do final do século XIX muitos pesquisadores da área de estudos culturais vem revelando os impactos ambientais que a concentração urbana, a industrialização promoveram nas cidades através do lixo, dos poluentes na água, nas sonoridades das ruas, nas formas de morar, nos tipos de pavimentação das ruas, nas maneiras de cuidar da vida (saúde $X$ doença) e da morte, dentre tantos outros temas caros à crônica urbana. Enfim, penso que estamos assistindo neste encontro muitas destas questões em que a cidade passou a ser palco de conflitos permanentes com a natureza. Analisando a questão cidade e natureza, através dos olhos do historiador, podemos dizer que o nosso passado de grande cidade é uma boa chave para percebermos as origens do seu caráter, mas também para pensarmos temas que permanecem repercutindo na atualidade e, sem nenhuma pretensão de vidência, permanecerão em seu futuro.

Talvez alguns historiadores possam estranhar a inclusão do presente e do futuro como algo a ser integrado em suas colaborações. Na maior parte das vezes, ao contrário de outros especialistas mais vinculados ao aqui e agora e ao futuro, o historiador permanece na retaguarda dos acontecimentos, de costas para o porvir. Com esta perspectiva, muitos historiadores acabam se restringindo em narrar algo que aconteceu no passado. O presente, lugar que pertencem, e o futuro, o vir a ser dos fatos, feito e refeito no dia a dia, volta-se para áreas bastante distantes da história.

É mais frequente vermos ambientalistas, físicos, biólogos, matemáticos, estatísticos, urbanistas ou mesmo meteorologistas analisando os desiquilíbrios ambientais do que historiadores.

A perspectiva das "ciências duras" em relação ao passado acontece, a grosso modo, na medida que os registros anteriores possam ser traduzidos em códigos numéricos e transformem-se em frequências e estatísticas. Esta análise das repetições das mesmas ocorrências ou fatos transformados em quantidades numéricas, tabelas e cálculos estatísticos parecem ser de fundamental importância na compreensão da 
maneira como passado, presente e os possíveis futuros se articulam. Porém, esta forma de apreciação, ao avançar sozinha diante dos fatos, acaba por ser parcial e ilusória.

Os acontecimentos do passado, sem a complexidade dos dias, sem as amarrações do tempo, perdem grande parte de sua vitalidade. As tabelas, frequências e estatísticas tem uma função fundamental ao quantificar eventos e apontar sua previsibilidade no tempo, porém seu universo seria muito mais amplo e colorido, se estivesse vinculado a narração dos acontecimentos.

Caso exemplar desta ausência de uma paisagem da história na previsão dos fatos, pode ser visto de forma bastante frequente através da divulgação na imprensa de alguma catástrofe natural.

No momento que escrevo este artigo, assisto na televisão ao incêndio do Museu da Língua Portuguesa e de parte da estrutura da Estação da Luz em São Paulo. Do passado é resgatado a lembrança de um outro incêndio ocorrido na mesma Estação em 1946. Porém, a alusão ao evento anterior, não tem a menor pretensão de encaminhar uma investigação mais profunda dos vínculos entre presente e passado, das implicações do Estado na guarda e vigilância dos bens públicos e outras tantas questões que podem surgir ao perscrutarmos os registros históricos de um evento.

A presença do incêndio anterior na Estação da Luz apenas serviu para acentuar as cores do atual, não para ser um instrumento de investigação eficaz a fim de compreender um fenômeno que parece se repetir em vários bens públicos tanto no presente como no passado. O "presentismo" se sobrepõe a prospecção histórica e, a conexão com o passado, se perde rapidamente por falta de uma investigação temporal mais cuidadosa.

Os eventos do passado, quando surgem na grande imprensa, simplesmente servem de ilustração para afirmações do próprio presente. Destituídos de qualquer singularidade e arrancados do seu contexto histórico, tornam-se quase "curiosidades" e repetições impertinentes dos outros tempos.

Como afirma E.H. Carr em What is History?:

se pudermos ampliar o âmbito de experiência além do que nós como indivíduos encontramos, se pudermos recolher as experiências de outros que se confrontaram com situações comparáveis no passado, então - embora não haja garantias - nossas chances de agir com sabedoria aumentariam proporcionalmente.( GADDIS, 2003 , p.23)

O desafio que resolvi me colocar nesta apresentação é exatamente mostrar como os posts sobre cidade e natureza do blog Versão Paulo buscam dialogar com os tempos 
na representação da história da cidade. Nesta interação, a previsão de futuro não é exata. Mas afinal, se não é rigorosa, o que uma análise histórica dos fenômenos da natureza no meio urbano pode contribuir para o presente e futuro das cidades?

O blog Versão Paulo nasceu da proposta de apanhar no presente questões emblemáticas que ocorrem na cidade e buscar no passado suas balizas temporais. Temas como a morte, as inundações, secas, buracos, sonoridades, rios, terrenos baldios, o lixo, o calçamento e outros tantos assuntos que nos surpreendem todo dia na crônica urbana, tornaram-se assuntos dos posts a serem pensados em sua longa duração.

O próprio título do blog, Versão Paulo, já é uma via de mão dupla: ver a cidade de São Paulo, abordar uma versão ou acontecimento relativo à cidade, jogá-lo no tempo a fim de construir um caminho profundo para repensar o assunto emergente no presente e comparar os eventos através de temporalidades diferentes.

A linguagem coloquial e o texto enxuto com que são elaborados os posts, também tem o propósito de ampliar o público leitor que se interessa por cultura urbana. A ideia é oferecer conteúdos que mostrem a pesquisa acadêmica atual, mas que não se restrinjam ao universo acadêmico.

Tentarei mostrar nesta apresentação como a produção dos textos do blog Versão Paulo são elaborados.

Selecionei alguns posts que abordam o desequilíbrio da natureza em sua relação com a urbanização, tais como: o calçamento urbano, a falta de água, a crise hídrica e a história do abastecimento de água na cidade de São Paulo.

Através da apresentação dos posts, explicarei como se constrói o diálogo entre escalas temporais diferentes. A ideia do blog parte sempre da abordagem de um assunto que é de conhecimento geral do público leitor. Normalmente os temas dos posts estão vinculados a questões emergentes no cotidiano urbano, os quais tomam relevância na mídia impressa.

O diálogo frequente com os meios de comunicação surgiu por conta da minha pesquisa de doutorado sobre a história da imprensa de humor no início do século XX. O funcionamento desta imprensa humorística era lançar um tema - normalmente uma questão já publicada em primeira mão na grande imprensa ou compartilhada no dia-a- 
dia da cidade - e, através de repetição do assunto em debate, a narrativa humorística reaproveitava os fatos apresentando os mesmos de pontos de vista totalmente diversos ${ }^{1}$.

Ao mesmo tempo em que se poderia rir da caricatura de um "problema urbano", a maneira como o humor se apropriava da questão, sem dúvida provocava nos leitores mais do que a diversão da risada inicial, mas também a reflexão crítica sobre determinados fatos presentes na cidade.

Por outro lado, para o pesquisador do presente, compreender do que riam os leitores da cidade de São Paulo no início do século XX não foi tarefa fácil, porque o humor se caracteriza exatamente por ser algo compartilhado por todos, datado e contextualizado.

Como afirma John Lewis Gaddis no primeiro capítulo do livro Paisagens da História, pesquisar o passado é aceitar com inteligência e perspicácia que adentramos um país estrangeiro e perguntarmos sempre "Que país, amigos, é este? " (GADDIS, 2003, p.31).

No caso dos registros caricaturais dos "problemas urbanos" no passado da cidade de São Paulo, o humor acabou por proporcionar uma maneira bastante eficaz de nos situarmos num país estrangeiro, pois estes, na maior parte dos textos e imagens abordados na narrativa humorística da imprensa do início do século XX, têm ligação direta com as questões da cidade atual. Assim, ao investigar o passado através do humor, foram "os problemas urbanos" que facilitaram minha aproximação com o universo da imprensa de narrativa irreverente.

Guardadas as devidas singularidades de cada época - atropelamentos, buracos, incêndios, inundações, falta de água, péssima pavimentação das ruas, taxa de lixo e colisões, foram assuntos que atravessaram o século $X X$.

Ao adentrar o universo da cidade através dos "problemas urbanos" representados pela narrativa irreverente, a primeira surpresa que tive foi perceber que São Paulo de antigamente não era nada pacata, mas repleta de problemas e contrastes. $\mathrm{O}$ humor das revistas do início do século $\mathrm{XX}$, provocava ruídos em outros registros históricos que valorizam muito mais o enaltecimento dos "velhos tempos" do que seus aspectos conflitantes. ${ }^{2}$

\footnotetext{
1 Janovitch, Paula Ester. Preso por Trocadilho: a imprensa de narrative irreverente paulistana (1900-1911). São Paulo: Editora Alameda. 2006

2 Penso que este viés mais nostálgico em relação ao passado, surge com frequência nos registros históricos memorialísticos e nas crônicas.
}

(c) Urbana: Rev. Eletrônica Cent. Interdiscip. Estud. Cid.

Campinas (SP)

v.8, n.2 [13]

p.28-43

ISSN 1982-0569 
A partir desta experiência nada nostálgica que os registros humorísticos ofereceram, os "problemas urbanos" passaram a ser encarados como uma temática histórica de longa duração que surgiu de forma bastante aguda no início do século XX com a industrialização e o crescimento da cidade. Permaneceu de forma recorrente e conflitante, tomando outros formatos na cidade até os dias de hoje.

Com esta perspectiva, podemos pensar os "problemas urbanos" como fatos históricos que traçam caminhos e mostram alternativas ao longo do tempo que podem ser indícios qualitativos na maneira como as questões foram vistas, os problemas solucionados ou não, e, de que forma estes vários eventos ocorridos no passado da cidade, podem nos oferecer uma maior consciência sobre a produção de novos parâmetros ao pensarmos eventos de ordem semelhantes no presente e o futuro desta mesma cidade.

Lembro aqui de um post específico que me parece bastante esclarecedor - "O calçamento de São Paulo: buracos e etc..."3 publicado em 2007 - momento em que a Prefeitura da cidade estava substituindo o piso das calçadas da área central. À época, a imprensa divulgou muito o assunto, inclusive começaram a sair nos jornais imagens de calçadas com o piso recém colocado, totalmente danificado.

Percebendo esta mesma questão no passado, podemos ver que as reformas e o calçamento das ruas de São Paulo, desde o final do século XIX, não ocorreram sem conflitos e problemas também. Inúmeras críticas saíram na imprensa de humor comentando o assunto no final do século XIX e no início do séc. XX. Desde os tipos de piso próprios para a circulação de automóveis, até a qualidade dos materiais e seu preço.

O debate foi tão acalorado que, em 1866, no Semanário humorístico Cabrião, publicado pelo ilustrador Agostini, surgiu na coluna "Gazetilha" um personagem cujo nome era o próprio material usado no calçamento, Dr. Pedregulho:

DR. PEDREGULHO - Corre como certo que este hábil engenheiro vai ser contratado para macadamizar as principais ruas da capital. É uma importante acquisição que vai fazer o município, porque é proverbial a perícia daquele engenheiro em matéria de apedregulhamento e aceio das ruas, praças e etc..., fazendo todo e qualquer serviço deste gênero com espantosa economia para os cofres públicos. (AGOSTINI, 2000, p.11).

3 Acessar o post "O calçamento de São Paulo: buracos e etc..." no endereço eletrônico https://versaopaulo.wordpress.com/2007/01/14/o-calcamento-de-sao-paulo-buracos-e-etc/ 
$E$, no século $X X$, com a cidade em metropolização acelerada, as tiradas humorísticas com o calçamento urbano só aumentaram. A revista humorística Juca Pato, de 1927, abusava da situação das ruas da cidade apelidando São Paulo de "buracolandia".

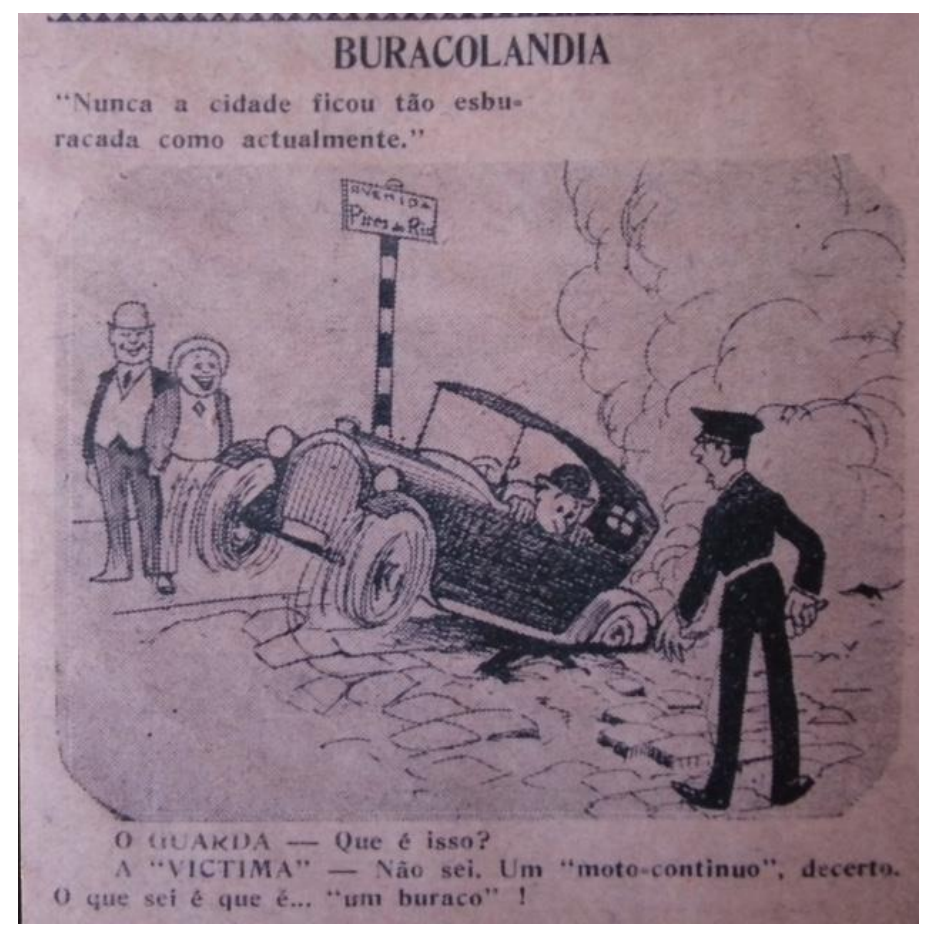

Figura 1 - Ilustrador: Belmonte. Fonte: Juca Pato, São Paulo, 1927

A reflexão profunda deste post, ao articular passado e presente, busca mostrar não apenas a constatação que o problema de pavimentação das vias públicas surgiu há mais de um século, mas perceber como ao longo do tempo a questão foi vivida e percebida de maneiras diversas.

Neste caso, a singularidade de épocas distintas apontou para um desejo da população por melhorias das ruas da cidade nos outros tempos, porém quando gerido pela administração pública, acabou resultando em novos problemas devido a qualidade do material e a diversidade com que o calçamento foi sendo colocado na área central da cidade. A conclusão do post é um trocadilho com a expressão "o buraco é mais embaixo", o que não deixa de seguir o tom dos registros humorísticos reunidos do passado em diálogo com o presente e, oferecer ao leitor, a possibilidade de reflexão sobre a diversidade de maneiras como o assunto foi tratado em épocas passadas.

A crise hídrica, que ainda permanece como uma questão problemática na cidade de São Paulo, foi motivo de quatro posts diferentes do blog Versão Paulo devido a sua 
longa duração ${ }^{4}$. Desde 2014 a escassez de água vem sendo pauta de discussões nos meios de comunicação, assim como no cotidiano dos cidadãos paulistanos.

Para a produção dos posts, a riqueza da crise oferecia tantos diálogos com o passado, que acabou formando entre si uma história do abastecimento de água na cidade de São Paulo.

Os quatro posts estão em sequência cronológica. O primeiro deles, publicado em 4 de julho de 2014, tem como título uma pergunta, "Será possível que ainda chova?"5 Este título surgiu de um dos capítulos do livro do historiador Affonso A. de Freitas, Tradições e Reminiscências Paulistanas, e trata da influência tupi-guarani sobre o português na forma de se construir uma sentença interrogativa. O título do post em forma de pergunta era bem oportuno para um momento em que a imprensa divulgava a questão da seca expressando uma forte expectativa em relação as chuvas. Todos esperavam com muita fé a previsão de chuvas na cidade. Ao mesmo tempo, a dúvida se ia chover ou não, também dominava o pensamento dos habitantes de São Paulo.

A ideia do título foi fazer uma reflexão sobre como esta dúvida, existente na cidade em 2014, poderia ser a porta de entrada para as interrogações relatadas na imprensa em 1867. Como a expectativa de chuvas diante de um período de seca foi vivenciada a 147 anos atrás e que diálogos momentos tão distantes poderiam manter entre si?

Na análise de Freitas, a questão era em parte respondida pelo governo da província com fé e rezas para que a chuva caísse sobre a cidade. Porém, para a população e para a imprensa, esperar a vontade divina era uma medida paliativa para um problema que vinha se arrastando por conta do abandono do governo em relação à administração da cidade. (FREITAS, 1978)

A caricatura do ilustrador Agostini destacou esta crítica da população em relação a atitude passiva da administração pública.

4 Outra característica bastante marcante da imprensa de narrativa irreverente paulistana do início do século $\mathrm{XX}$, foi prolongar o debate de questões conforme o impacto e permanência destas em pauta nos jornais diários da cidade.

5 Acesse o post "Será possivel que ainda chova? através do endereço eletrônico https://versaopaulo.wordpress.com/2014/07/09/sera-possivel-que-ainda-chova-re-ti-sera/ 


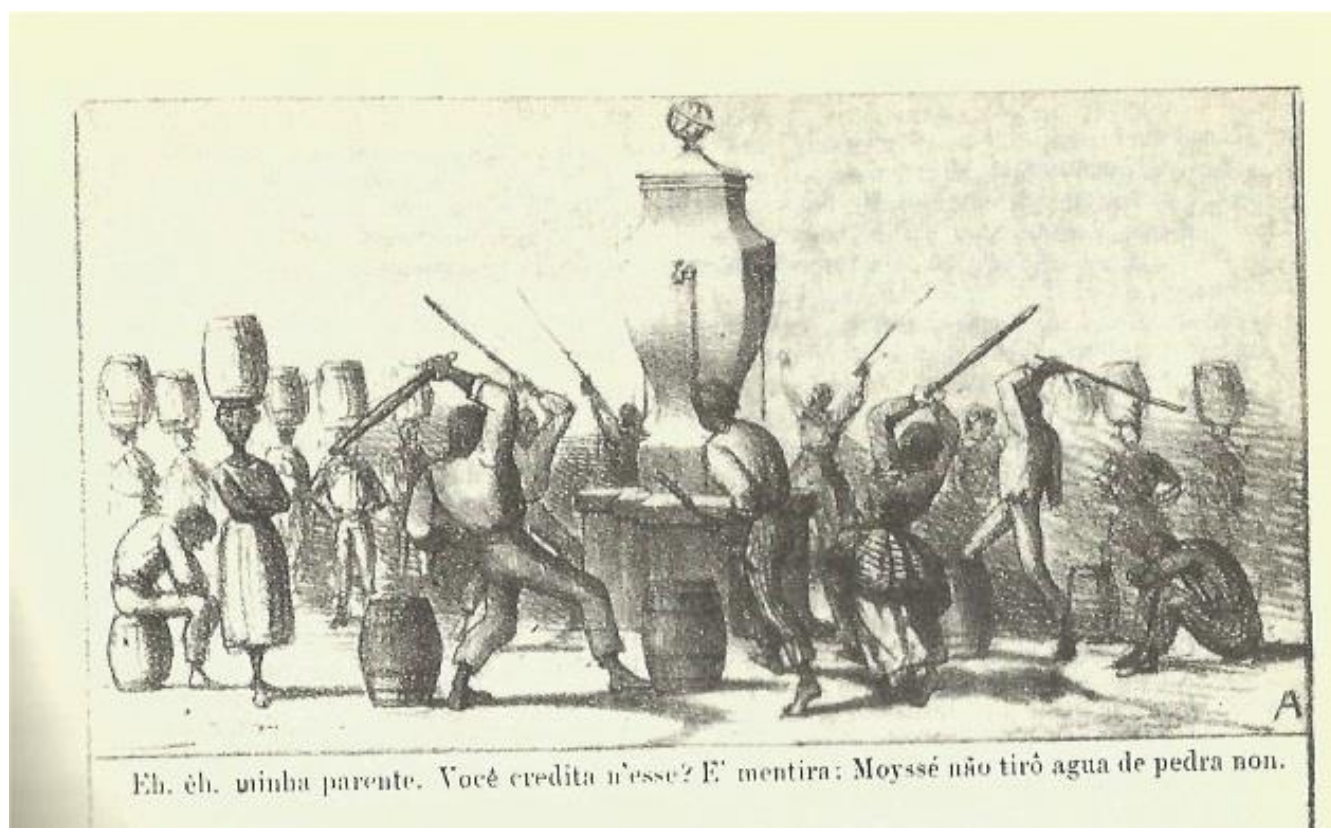

Figura 2 - Ilustrador: Angelo Agostini. Fonte: Diário de São Paulo, 28/02/1867

Com o título de "Novo Moises", a ilustração de Agostini aconselhava os paulistas a baterem com varas no chafariz a fim de obterem água. Assim como na passagem bíblica, o milagre não ocorreu e São Paulo sofreu uma das maiores secas de que se tem registros durante o século XIX.

No post do blog Versão Paulo o leitor além de tomar consciência da mesma questão da falta de água há 147 anos, percebe que tanto naquele momento como no atual, o governo continuava a torcer para que chovesse. Porém, as semelhanças se desfazem no momento em que se contextualiza com maior precisão histórico o que de fato ocorreu em 1867 para que a população e a imprensa estivessem manifestando tanta insatisfação em relação a administração pública quanto a escassez de água na cidade.

O problema da água em 1867 surgiu um pouco antes do sistema Cantareira ser implantado em São Paulo. Naquele momento, o Presidente da Província dava mais atenção a Guerra do Paraguai em detrimento da administração da cidade. O abandono do meio urbano por parte do governo talvez respondesse a falta de crença da população e da imprensa quanto a solução do problema da escassez de água. Ao mesmo tempo, surgiam novos projetos que deixavam a população na expectativa que um outro sistema de abastecimento viesse a sanar os problemas de falta de agua na cidade alimentada até então por chafarizes, bicas e rios. 
O segundo post da crise hídrica tem o título "Entramos pelo cano"6. É um jogo de palavras, um trocadilho entre passado e presente. A situação da crise hídrica perdurava na cidade e todas as atenções se voltavam para a Sabesp. O Sistema Cantareira passou a ser esmiuçado. Aliás, penso que grande parte dos habitantes de São Paulo, em meados de outubro de 2014, passaram a conhecer os locais que abasteciam a cidade, justamente pela escassez de água e do profundo debate que se fez nos meios de comunicação.

A água como falta passou a ser a grande protagonista da cidade em 2014. A expressão "Entramos pelo cano" é uma chamada literal para a realidade daquele ano. E, com este título, o post convida o leitor a conhecer o começo da implantação do Sistema Cantareira na cidade de São Paulo há mais de cem anos.

Através da caricatura de Voltolino "Agua de S. Paulo" de 1920, já estamos diante do Sistema Cantareira implantado. O que será que estava acontecendo na cidade naquele momento para o caricaturista mostrar os canos todos remendados?

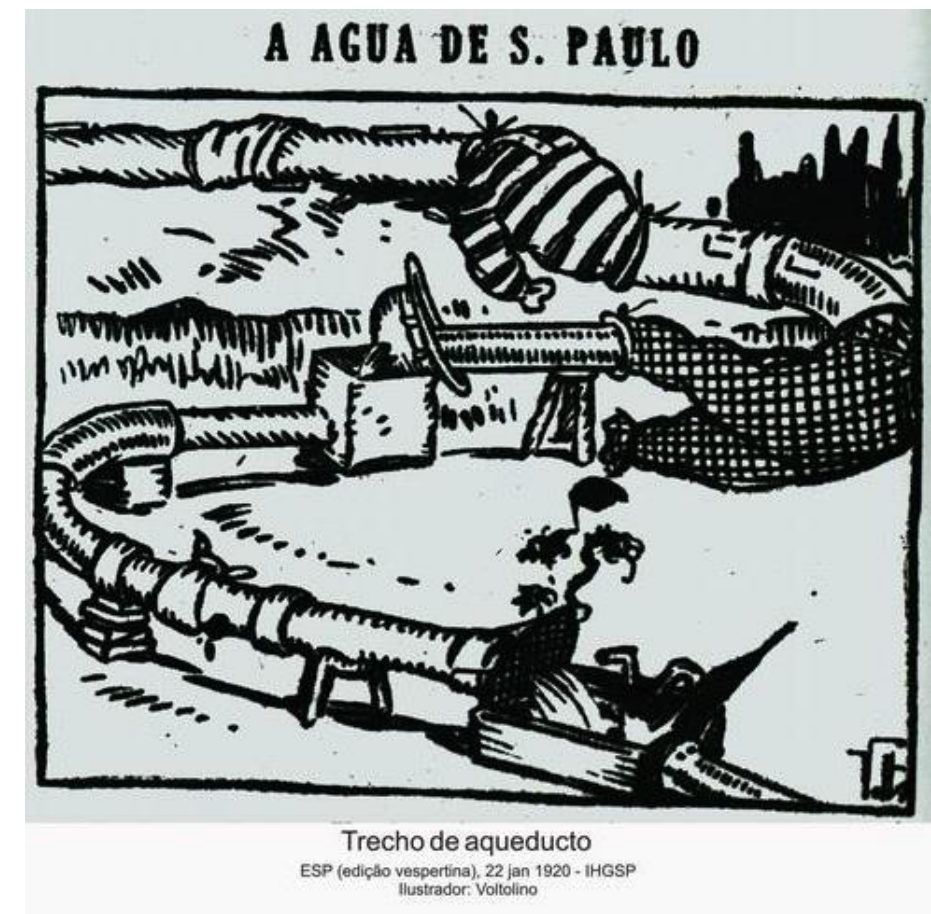

Figura 3 - Ilustrador: Voltolino. Fonte: Estado de São Paulo, 22/01/1920

Quando o historiador não consegue compreender algo nos limites temporais estabelecidos em sua pesquisa, ele se utiliza de um artifício que é muito comum na

6 Acessar o post "Entramos pelo cano" pelo endereço eletrônico https://versaopaulo.wordpress.com/2014/10/27/entramos-pelo-cano/

(c) Urbana: Rev. Eletrônica Cent. Interdiscip. Estud. Cid. $\quad$ Campinas (SP) $\quad$ v.8, n.2 [13] $\quad$ p.28-43 ISSN 1982-0569 
pesquisa histórica: o recuo no tempo. Buscar o passado dos eventos em foco e, tentar através deste retrocesso, ter mais elementos para perceber o que poderíamos chamar de futuro do passado.

Foi o que ocorreu no post "Entramos pelo cano", ao recuar alguns anos, conseguimos mostrar o início do Sistema Cantareira em 1877, quando estava nas mãos de uma empresa privada, porém, por falta de planejamento, o abastecimento tornou-se falho e restrito a determinadas regiões.

Além das falhas no recém implantado sistema de abastecimento, fica-se sabendo que naquele momento a água deixou de ser um bem natural, gratuito e compartilhado por todos, e passou a ser paga. O "Entramos pelo cano" se torna literal. Ninguém mais escapa de consumir água encanada como uma mercadoria. Vários chafarizes públicos são desativados na cidade e a água dos rios está cada vez mais contaminada pelo aumento dos produtos industrializados.

Em 1893 o Estado assume a administração do Sistema Cantareira (RAE) sob a direção de José Pereira Rebouças. Entretanto, a água continuou a faltar nas torneiras das casas, uma hora os canos não se encaixavam, outra, eram os entupimentos constantes que impediam o fluxo pelas tubulações subterrâneas. Enfim, entramos pelo cano!

O terceiro post serve apenas para realçar a função da torneira, objeto fartamente utilizado na modernidade, mas que merece ser investigado em sua história e presença nas habitações ao refletirmos historicamente sobre a escassez da água e a presença das novas tecnologias no início do século XX.

O título "1924 - Ano em que as torneiras viraram cabides"7 faz referência a uma curta crônica de Afonso Schmidt que segue no post. O escritor comenta que após a Revolução de 1924 ocorreu uma grande seca na cidade e os proprietários de casas para alugar passaram a colocar anúncios com os seguintes dizeres: "com água na torneira". Seria a água naquele momento raridade nas casas ou propaganda enganosa dos proprietários?

A caricatura que segue no mesmo post foi publicada alguns anos antes da crônica de Afonso Schmidt, mas decidi por coloca-la pois mostra três torneiras e duas mulheres disputando a escassa água da cidade. As três torneiras representam, cada uma delas,

7 Ver post "1924 - Ano em que as torneiras viraram cabides" no endereço eletrônico https://versaopaulo.wordpress.com/2014/11/03/1924-ano-em-que-as-torneiras-viraram-cabides/ 
um bairro pobre da cidade de São Paulo. Todos os três bairros ficam na parte baixa da cidade, onde a água faltava com mais constância do que nas regiões altas.

"Bellezas", título da caricatura de Voltolino, também faz uma paródia às fotografias e registros que ilustram os embelezamentos do centro de São Paulo no início do século $X X$. No caso desta caricatura, a grande beleza da cidade, nos bairros pobres, seria o avesso daquilo que ocorria nas fotos capturadas na área central da cidade, onde mulheres bem trajadas desfilavam em trottoir pelas calçadas. Ainda na legenda da ilustração, o caricaturista destaca a divisão de espaços e distinções de classes ao brincar com o duplo sentido da palavra repartição: " Da Repartição das Águas".

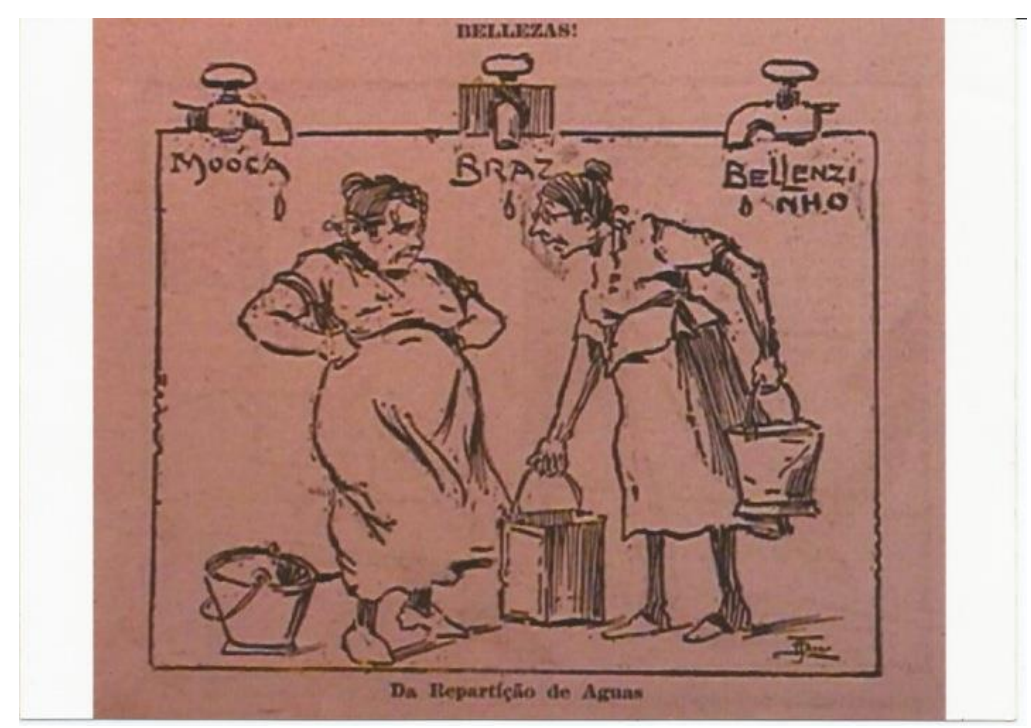

Figura 4-Ilustrador Voltolino. Fonte: A Ronda, 27/07/1908

O quarto post, "Fechar a torneira", utiliza-se da "torneira" do post anterior e fecha o ciclo da série sobre a história do abastecimento e escassez de água na cidade. ${ }^{8}$

Em janeiro de 2015 estávamos num outro momento da questão da escassez de água. Surgem nos meios de comunicação várias alternativas a fim de que o cidadão possa contribuir para a redução do uso da água. Todo mundo que mora em São Paulo provavelmente fez alguma coisa em relação a economia de água. Encheu baldes, reutilizou a água da máquina de lavar roupas para limpar a casa e o quintal e etc... A própria expressão "reuso da água" entrou em moda e parece que vai demorar para sair de cartaz.

8 Acessar o post "Fechar a torneira" no endereço eletrônico https://versaopaulo.wordpress.com/2015/01/30/fechar-a-torneira-2/.

(c) Urbana: Rev. Eletrônica Cent. Interdiscip. Estud. Cid.

Campinas (SP)

v.8, n.2 [13] p.28-43

ISSN 1982-0569 
O título do post tem relação com o momento atual de economia de água, mas a caricatura do homem barrigudo, deitado na banheira, reclamando porque pagou por um banho inteiro e ficou com a pança a seco, é do final do século XIX.

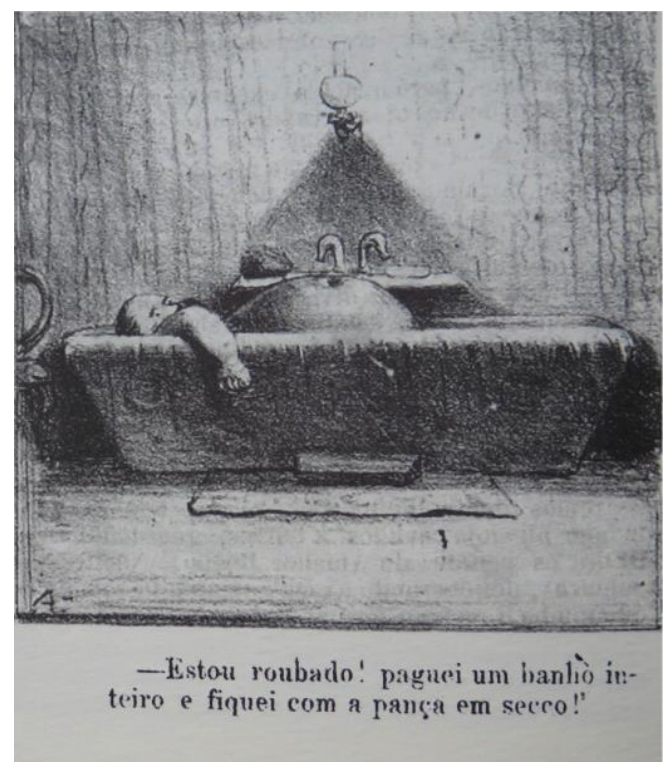

Figura 5 - Ilustrador Agostini. Fonte: O Diabo Coxo, 06/10/1908

Se formos analisar esta caricatura através dos nossos hábitos atuais, sem dúvida vamos "entrar pelo cano". Mais uma vez a prospecção histórica nos coloca em diálogo com o passado de maneira que percebamos entre os tempos, mais distinções, singularidades, do que aparentes semelhanças. Estas distinções fazem parte do fértil diálogo temporal.

"As aparências enganam", e o que imaginávamos ser parte de uma longa tradição nacional, o hábito de tomarmos banhos em abundância, assim como o de lavarmos a casa e as calçadas com muita água, não passa de uma "tradição inventada". 9

A conversa entre passado e presente se faz por diferenças e, desta contraposição, surge certa desmistificação em relação aquilo que parecia ser parte de nossa identidade, os banhos em abundância e o uso da água na limpeza doméstica.

Através do livro da historiadora Denise Sant'Anna , Cidade das Águas, e do francês George Vigarello, O limpo e o sujo: uma história da higiene pessoal, procuro mostrar

\footnotetext{
9 Eric Hobsbawm eu seu livro A Invenção das Tradições ,classifica em três categorias as tradições inventadas desde a Revolução Industrial, dentre elas a que cabe aqui é "aquela cujo propóstico principal é a socialização de idéias, a inculcação de idéias, sistema de valores e padrões de comportamento". ( HOBSBAWN, 1984, p.17)
}

(c) Urbana: Rev. Eletrônica Cent. Interdiscip. Estud. Cid. $\quad$ Campinas (SP) $\quad$ v.8, n.2 [13] $\quad$ p.28-43 ISSN 1982-0569 
que nem sempre o brasileiro tomou muito banho. Especialmente, no período em que a caricatura de Agostini foi publicada. Havia naquele momento um certo temor quanto ao ato de tomar banho. As pessoas tinham medo de se afogar, ou mesmo, do excesso de água ser prejudicial a saúde.

A ideia de limpeza à seco também era muito utilizada na maneira de escovar os dentes: usava-se fumo na escovação e no asseio da casa. Encontramos o uso de vassouras e de panos úmidos, mesmo que as casas tivessem fontes de água.

Porém, o fundamental do post não é pensar nas variadas formas como o século XIX e início do XX se utilizavam de outras alternativas para a limpeza e higiene, mas perceber que as distinções revelam que algo mudou radicalmente nos hábitos daquele período para os tempos atuais. E com certeza, a presença das novas tecnologias, influenciaram e muito a forma de lidarmos com aquilo que até então era um bem natural, gratuito e que os nossos antepassados usavam com muito mais parcimônia do que nós.

Neste sentido me parece que o passado indica algo surpreendente. Foi no início do século XX que foram introduzidas nas casas os modernismos higiênicos, tal como as torneiras, descargas automáticas, banheiras e chuveiros.

Por um lado, toda esta parafernália facilitou e muito a vida da população que não precisaria mais carregar a água em baldes. Mas, por outra lado, a água encanada que chegava em casa, facilmente disponível nas torneiras e outros artefatos do lar, estimularam os habitantes modernos a usar cada vez mais água, talvez mais do que o necessário.

Assim, a reflexão do título do post volta-se novamente para um diálogo entre o passado e o presente. Teremos que aprender a economizar água pensando nesta longa duração da história da escassez de água na cidade.

O conforto da casa trouxe com ele uma mudança radical de hábitos e, em consequência direta, o desperdício deste liquido tão precioso para vivermos. Retornamos ao presente com o título "Fechar a torneira" e enriquecidos com os mais variados caminhos que o passado oferece neste ir e vir entre os tempos.

E aqui finalizo estas análises breves dos posts do blog tentando refletir com vocês sobre a contribuição do historiador nesta tarefa de aproximar o diálogo entre presente e passado pensando novas perspectivas para o futuro. Não estaria o historiador justamente neste ato de ir e vir de tempos, na "retaguarda dos fatos", fazendo previsões importantes para o futuro das cidades? 
Diz John Lewis Gaddis que "o estudo do passado não é um guia seguro para predizer o futuro. Porém, ele nos prepara para o futuro, expandindo nossa experiência, fazendo com que possamos aumentar nossas habilidades, nossa energia - e se tudo for bem, nossa sabedoria. Embora possa ser verdade, como Maquiavel escreveu, 'que a sorte é o árbitro de metade das nossas ações', assim também 'ela deixa a outra metade, ou quase isso, para nós governarmos. Ou como ele ainda apontou: "Deus não quer fazer tudo sozinho." (GADDIS, 2003, p.25)

Acredito que o diálogo entre os tempos, maneira como o historiador concebe sua forma de compreender e representar seus objetos de análise, não apenas nos aproxima do passado de nossas questões atuais, mas coloca o registro deste passado em diálogo com as decisões e atitudes que tomamos no presente.

Neste sentido, apesar de ser muito complexa a articulação dos múltiplos saberes ao refletirem juntos questões relativas à cidade e seus embates com a natureza, penso que a integração das várias disciplinas torna não só o debate mais frutífero, mas também, a medida que vamos tomando consciência dos caminhos percorridos do passado: das semelhanças, diferenças e distinções entre os tempos, temos muito mais possibilidades de fazer melhores escolhas para o presente e o futuro das cidades.

Maquiavel sugeriu que "Deus não quer fazer tudo sozinho". Penso que a investigação histórica, por ter como característica fundamental o diálogo entre os tempos, deve se integrar ao debate atual sobre meio ambiente e cidade e participar com suas especificidades nos temas do presente urbano e nas projeções dos possíveis futuros.

\section{Bibliografia final:}

AGOSTINI, Angelo. Cabrião: Semanário humorístico editado por Ângelo Agostini, Américo de Campos e Antonio Manoel dos Reis, 1866-1867. São Paulo: Editora Unesp/Imprensa Oficial, 2000.

FREITTAS, Afonso A. Tradições e reminiscências paulistanas. São Paulo: Governo do Estado de São Paulo, 1978.

GADDIS, John Lewis, Paisagens da História: como os historiadores mapeiam o passado. Rio de Janeiro: editora Campus. 2003 
JANOVITCH,Paula E. Blog Versão Paulo: www.versaopaulo.wordpress.com

JANOVITCH, Paula E. Preso por Trocadilho: a imprensa de narrativa irreverente paulistana 1900-1911. São Paulo: Editora Alameda. 2006

HOBSBAWM, Eric. A invenção das tradições. Rio de Janeiro: Editora Paz e Terra. 1984

SANT'ANNA, Denise Bernuzzi de. Cidade das Águas: usos de rios, córregos, bicas e chafarizes em São Paulo (1822-1910). São Paulo: Senac. 2007.

VIGARELLO, Georges, o Limpo e o Sujo: uma história da higiene corporal. São Paulo: Martins Fontes, 1996. 